\title{
TTR
}

Traduction, terminologie, re?daction

\section{Francisco Lafarga (dir.). El teatro europeo en la España del siglo XVIII. Lleida, Universitat de Lleida, 1997.}

\section{Marc Charron}

Volume 11, numéro 1, 1er semestre 1998

Diachronie et synchronie

Diachronics and Synchronics

URI : https://id.erudit.org/iderudit/037326ar

DOI : https://doi.org/10.7202/037326ar

Aller au sommaire du numéro

\section{Éditeur(s)}

Association canadienne de traductologie

ISSN

0835-8443 (imprimé)

1708-2188 (numérique)

Découvrir la revue

Citer ce compte rendu

Charron, M. (1998). Compte rendu de [Francisco Lafarga (dir.). El teatro europeo en la España del siglo XVIII. Lleida, Universitat de Lleida, 1997.] TTR, 11(1), 255-258. https://doi.org/10.7202/037326ar d'utilisation que vous pouvez consulter en ligne.

https://apropos.erudit.org/fr/usagers/politique-dutilisation/ 


\section{Francisco Lafarga (dir.). El teatro europeo en la España del siglo XVIII. Lleida, Universitat de Lleida, 1997.}

Dans son introduction à El teatro europeo en la España del siglo XVIII, Francisco Lafarga dresse un bilan des études portant sur la traduction théâtrale dans l'Espagne du XVLI' siècle, en évoquant d'entrée de jeu "l'histoire quasi centenaire " de ce champ d'intérêt. Ce nouvel ouvrage se distingue cependant des travaux antérieurs en ce qu'il tente d'offrir une * vision d'ensemble de la présence du théâtre étranger dans l'Espagne du XVIII' siècle ".

L'ouvrage se divise en trois parties : la première porte essentiellement sur la diffusion de la théorie théâtrale étrangère; la deuxième, qui comporte six chapitres rédigés par six chercheurs différents, est consacrée à la traduction mais plus encore à la réception, dans leurs versions traduites, des comédies, tragédies et drames étrangers (surtout français et italiens); enfin, la troisième partie, qui fait plus de la moitié de l'ouvrage, est un catalogue exhaustif des traductions se rapportant à chacun des six chapitres susmentionnés. L'ouvrage compte aussi un index des auteurs, traducteurs et compositeurs, ainsi qu'une 
bibliographie générale où figurent surtout des études récentes sur des traductions théâtrales.

La première partie, rédigée par Inmaculada Urzainqui et intitulée "Poética teatral : presencia y prestigio de los críticos extranjeros ", traite à la fois de l'influence de la critique étrangère sur les écrits théoriques espagnols et du rôle joué par les traductions espagnoles proprement dites d'ouvrages theoriques européens. Quoique cette présence critique (essentiellement française) demeure indéniable, son prestige ne vient pas éclipser totalement l'école de pensée espagnole. Les deux « poétiques * convergent en fait vers un objectif commun, soit la réforme et la dignificación de la scène espagnole. Urzainqui soutient qu'il serait ainsi erroné de conclure à l'avènement d'une réforme théátrale passant exclusivement par la France, puisqu'elle est tout autant le fruit de l'effort de regénération poursuivi par les représentants de l'Illustration.

La deuxième partie, intitulée * La traducción y los géneros dramáticos ", dresse un tableau complet de l'activité traduisante en Espagne au XVIII ${ }^{\circ}$ siècle en ce qui concerne : les tragédies françaises (Juan Antonio Rios), les comédies françaises (Francisco Lafarga), les drames français (María Jesus Garcla Garrosa), les mélodrames de Metastasio (Patrizia Garelli), les comédies et les drames de Goldoni (Antonietta Calderone et Victor Pagán) et les pièces anglaises et allemandes (Francisco Lafarga).

En insistant sur les circonstances propres à la traduction théâtrale ayant cours au XVIII ${ }^{e}$ siècle, Ríos explique la position secondaire de la tragedie (tout particulièrement française), dans le système dramatique espagnol, par l'absence d'un public cultivé et par * la monotonie et la typification des thèmes et personnages " associées au genre. L'auteur termine son étude en analysant certains aspects des traductions des tragédies de Racine, de Comeille et de Voltaire.

Dans son analyse des traductions des comédies françaises, Lafarga établit d'abord en quoi se distinguent, au sein du système dramatique espagnol, les deux genres théâtraux \& reconnus » au XVIU ${ }^{e}$ siècle, soit la comédie et la tragédie. Il rappelle ensuite l'importance en Espagne de la comédie du Siècle d'or. L'auteur accorde une attention particulière aux sous-genres comiques et à leurs transformations, en 
consacrant une partie importante de son analyse à la réception des multiples formes du théâtre comique français.

García Garrosa montre, quant à elle, de quelle manière le drame surgit telle une forme theâtrale inédite dans le paysage littéraire de l'Espagne du XVIII' siècle. Ce genre nouveau est considéré " hybride", en ce sens qu'il vient s' insérer entre la tragédie et la comédie. Ainsi faut-il comprendre que ces * drames " regroupent les comédies larmoyantes, les genres sérieux, les tragédies bourgeoises, parfois même certaines comédies ou tragédies. L'auteure souligne qu'il est difficile, dans un tel contexte, d'établir les normes ayant servi de principes directeurs à l'activité traduisante. Le genre, quoique très populaire, demeure toujours une production culturelle " importée ", ce qui expliquerait entre autres pourquoi les traductions de drames sont trois fois plus nombreuses que les pièces $\alpha$ dramatiques n autochtones. Quant à la « qualité " des traductions, l'auteure estime que si la " fidélité quasi absolue " semble être le lot des premières traductions, on décèle une attitude beaucoup plus $\alpha$ libre $n$ vers la fin du siècle, attitude qui finira par * tendre à la proximité textuelle * au début du XIX' siècle.

L'analyse de Patrizia Garelli porte sur les traductions des mélodrames de Metastasio et, plus spécifiquement, sur la présence, dans la seconde moitié du XVIII ${ }^{c}$ siècle espagnol, de nombreuses adaptations de ces mélodrames sous forme de comédies, de tragédies ou de drames. Ces adaptations obtiennent la faveur populaire, contrairement aux traductions a officielles " sollicitées par le ministre Aranda, sans doute jugées trop élitistes par le grand public. Garelli souligne que le choix d'adapter n'est pas fortuit, puisque cela permet de représenter une tradition thêâtrale et une théâtralité nouvelle sur une même scène.

L'étude consacrée à Goldoni est divisée en deux parties : Antonietta Calderone traite des comédies, et Victor Pagán, des drames comiques. Le dramaturge italien étant l'auteur étranger le plus traduit dans la seconde moitié du siècle, l'impact de ses pièces sur la scène théâtrale espagnole est considérable. Calderone évoque les transformations que subissent les comédies au profit des réalités culturelles, historiques et théâtrales de la société réceptrice, et préfère même parler de connaturalizaciones des textes goldoniens (plutôt que de traductions ou d'adaptations). Quant à la réception des dramas jocosos de 
Goldoni, Pagán rappelle leur succès aussi bien dans les salles populaires que dans les salons aristocratiques. La présence du thêttre * chanté " de Goldoni conduit à une telle transformation du système dramatique espagnol que, pour la première fois, l'idéal ilustrado devient en soi un produit " consommable ", capable à la fois " d'éduquer et de divertir ".

Dans le chapitre qui vient clore cette deuxième partie de l'ouvrage, Lafarga évoque brièvement la situation de la traduction thêâtrale de quelques auteurs allemands (Schiller et Lessing) et présente surtout celle d'auteurs anglais (Addison et Shakespeare). On constate que leur présence demeure somme toute marginale en comparaison de celle des dramaturges français et italiens. Fait intéressant à noter : la première traduction publiée d'une pièce de Shakespeare (en l'occurrence, Hamlet) paraît en Espagne en 1798.

El teatro europeo en la España del siglo XVIII est un ouvrage qui intéresse davantage l'histoire de la traduction théâtrale que l'histoire critique de la traductologie théâtrale en Espagne. On reprochera peut-être à certains collaborateurs leur réticence à tirer des conclusions générales (qui s'imposeraient parfois), d'où l'éventuelle difficulté pour le lecteur de saisir le portrait d'ensemble que Lafarga affirme, dans son introduction, souhaiter présenter. Ceci dit, on ne peut que saluer la contribution de l'ouvrage à l'histoire culturelle du XVIII' siècle espagnol et européen ainsi qu'aux recherches documentaires en traductologie.

Marc Charron Université de Montréal 